\title{
DisTINÇÃO TEÓRICO-CLÍNICA ENTRE DEPRESSÃO, LUTO E MELANCOLIA
}

\author{
Maria Teresa da Silveira Pinheiro* \\ Rogerio Robbe Quintella** \\ Julio Sergio Verztman***
}

\section{Resumo}

Este artigo aborda os principais aspectos da depressão, na contemporaneidade, visando distingui-la do luto e da melancolia. Para isso, tomamos como eixo teórico a noção, por nós postulada, de crença narcísica (objeto por excelência do tipo de sintoma depressivo aqui abordado). Procuramos demonstrar que a presença hegemônica da crença narcísica na subjetivação pode levar a uma forma de reação à perda que se distingue tanto do luto quanto da melancolia. Este tipo de depressão apresenta-se como uma das principais formas de sofrimento psíquico que aparecem na clínica psicanalítica contemporânea.

Palavras-chave: depressão; crença narcísica; luto; melancolia; contemporaneidade.

\section{Abstract \\ THEORETICAL-CLINICAL DISTINCTION BETWEEN DEPRESSION, MOURNING AND MELANCHOLY. \\ This article approaches the main aspects of depression on contemporaneity and aims to distinguish it from mourning and melancholy. For this we take as theoretical axis the notion, by us postulated, of narcisic belief, object by excellence of the depressive symptom kind here}

* Psicanalista; Pesquisadora da UFRJ, Coordenadora do Núcleo de Estudos em Psicanálise e Clínica da Contemporaneidade (UFRJ).

** Psicólogo (UFF), Doutor (UFRJ); Membro do Núcleo de Estudos em Psicanálise e Clínica da Contemporaneidade (UFRJ).

***Psicanalista; Psiquiatra do IPUB-UFRJ, Doutor (UFRJ), Coordenador do Núcleo de Estudos em Psicanálise e Clínica da Contemporaneidade (UFRJ). 
approached. We search to demonstrate that the hegemonic presence of the narcisic belief on the subjective constitution may take to a form of reaction to loss that distinguishes from mourning and melancholy. This kind of depression presents itself as one of the main forms of psychic suffering that appear on contemporary psychoanalytic clinic.

Keywords: depression; narcisic belief; mourning; melancholy; contemporaneity.

Referenciado no campo psicanalítico, o presente trabalho visa situar, numa perspectiva teórico-clínica, as especificidades do sofrimento depressivo contemporâneo numa comparação com o luto e a melancolia - estes últimos, acontecimentos mais tematizados pela psicanálise. $\mathrm{O}$ tipo de depressão postulada neste trabalho exige intervenções pautadas pelo exame da subjetividade nos dias de hoje. Procuraremos demonstrar que esta forma de depressão apresenta importantes distinções da organização melancólica e requer dos psicanalistas esforços teóricos e terapêuticos para que seja efetivamente compreendida e tratada.

O elemento que nos servirá de guia para a distinção entre luto, depressão e melancolia será a noção, por nós postulada, de crença narcísica. Demonstraremos que a presença hegemônica desta crença determinará uma organização narcísica baseada numa ancoragem sintomática, cujo objetivo será: "rechaçar a impermanência" - manter uma estase sustentada por um tipo particular de idealização, que diz respeito ao investimento amoroso do outro parental. A crença narcísica referencia para o sujeito o ponto em que, mediante a incidência dos ideais e dos discursos parentais, a criança introjeta um "sentido de onipotência narcísica".

Nesses termos, a crença narcísica é um hiperinvestimento nas ideias de imortalidade e onipotência do eu, subjacentes à própria formação do eu-ideal. Revela-se como um modo de subjetivação que se sobrepõe à constituição do ideal do eu nos dias de hoje. Como veremos, esse tipo de crença, em torno da qual gravita boa parte do campo dos ideais na atualidade, implica num modo peculiar de reação à perda e à finitude que difere tanto do luto quanto da melancolia, passando a constituir um dos principais signos atuais do sofrimento psíquico.

Para efeito de circunscrição temática, privilegiaremos, neste artigo, a dimensão discursiva do mal-estar depressivo, um dos eixos que constituem a sua experiência subjetiva ${ }^{1}$. As distinções que objetivamos realizar entre a depressão contemporânea, o luto e a melancolia pautam-se nos modos como o sujeito se situará no discurso sobre si, o qual se tornará, em alguns casos, subjugado à crença narcísica. Partiremos da distinção discursiva entre o que se configura por "eu já fui algo ou alguém e hoje não sou mais" - presente na depressão (cf. Pinheiro, 2005) - e "eu não sou 
nada" ou "eu não sou nem nunca fui nada" - elemento discursivo específico da subjetivação melancólica (cf. Lambotte, 2001).

Localizaremos a especificidade do luto, situando esses três fenômenos subjetivos (luto, depressão e melancolia) como formas distintas de reação à perda² .

\section{BREVE PANORAMA SOBRE LUTO E MELANCOLIA NA PSICANÁLISE}

Na obra de Freud, o luto aparece tanto na sua exposição sobre a melancolia, como no estudo das sociedades primitivas ligado aos tabus que as organizam (Freud, [1913] 1996). Segundo Freud ([1917] 1996), o enlutado mantém-se temporariamente num estado de rebaixamento libidinal e sofrimento ante a morte ou a perda cujos efeitos se fazem valer pela possibilidade de dotar a dor de um término factível. O luto é evocado pelo sujeito no sentido de fazer com que a dor não se eternize, o que o define efetivamente como um "trabalho psíquico". Ratifica-se na obra de Freud que o trabalho do luto tem a função de elaboração e assimilação psíquica da perda, bem como de possibilitar a separação com relação ao objeto perdido e o reinvestimento num substituto. $\mathrm{O}$ enlutado martiriza-se pela perda, recorda-se constantemente do morto. Ele trabalha no sentido de dar um estatuto afirmativo a algo que se perdeu, bem como dotar este fato de um arcabouço simbólico.

Em "Luto e melancolia" ([1917] 1996), Freud descreve de maneira mais detida as características do processo de luto, visando distingui-lo da manifestação melancólica. Ali, ele considera que no luto prevalece uma inibição da atividade e do eu, uma "perda 'temporária' da capacidade de adotar um novo objeto de amor" (Freud, [1917] 1996: 250).

$\mathrm{Na}$ melancolia, a perda do objeto toma outro destino, distinto do luto. Ali, o objeto perdido é o próprio motivo da condição trágica do sujeito, na medida em que a ambivalência passa a assumir seu caráter violento na relação com o objeto. A ambivalência retrata uma forma de reação à perda cujo destino é o empobrecimento subjetivo. Identificado, paradoxalmente, ao objeto perdido (identificação narcísica), o sujeito entra num movimento de assassinato de si mesmo, deflagrando um jogo de forças que reveste de uma moral aviltante o ódio ao objeto (Freud, [1917] 1996: 250). Como resultado desse jogo de forças aparece a autoflagelação subjetiva, característica de um senso crítico sempre pronto a massacrar o próprio eu do melancólico.

Com efeito, o melancólico vê-se inteiramente absorvido pela perda e afirma de maneira violenta sua condição ante o próprio sofrimento. $\mathrm{O}$ melancólico despe-se ao extremo em seu discurso, referindo-se a si mesmo com a violência de 
quem odeia, rejeita ou deseja vingança. $\mathrm{O}$ eu do melancólico acede a um estatuto de vazio absoluto, no qual é desvelada a condição mesma da mortalidade, da fraqueza, da desvalia, do desprezo. "Ele se repreende" - diz Freud -, "se envilece, esperando ser expulso e punido. Degrada-se perante todos, e sente comiseração por seus próprios parentes por estarem ligados a uma pessoa tão desprezível” (Freud, [1917] 1996: 252).

A autoacusação, a autoflagelação e o movimento mortífero do melancólico em direção ao seu próprio eu revelam, para Freud, uma circunstância psicopatológica específica: o melancólico não faz o luto da perda objetal. Ele se identifica ao objeto perdido, numa situação que sinaliza um quadro narcísico peculiar. Isto coloca Freud na direção de uma abordagem metapsicológica diferenciada acerca desta disposição subjetiva.

A identificação melancólica caracteriza-se, a partir disso, não como uma identificação aos traços (identificação histérica), que tem como efeito a constituição de um precipitado de identificações (cf. Freud, [1923] 1996). Verifica-se que na melancolia a perda é recusada, e, através da identificação narcísica, o melancólico mantém o objeto dentro de si. Pinheiro (1993) assevera que: "Neste caso é como se a identificação trouxesse o objeto in toto, em bloco. $\mathrm{Na}$ ausência da dialética identificatória feita por traços, o objeto torna-se, por assim dizer, um posseiro que ocupa o espaço egoico, num projeto mimético e metonímico levado ao extremo" (Pinheiro, 1993: 53).

O estudo da melancolia na psicanálise conta com a contribuição de importantes autores. Discutiremos os trabalhos de Abraham e Torok ([1972] 1995), que procuraram esclarecer essa questão sob o ponto de vista do conceito de incorporação, além das proposiçôes de Lambotte (2001) sobre o discurso melancólico. A especificidade do problema concernente à identificação na melancolia revela precisamente que nesta o objeto não foi introjetado, mas foi incorporado. A noção de incorporação, presente nas teorias de Abraham e Torok, tem como referência fundamental o pensamento de Ferenczi, do qual se extrai o conceito de clivagem articulado à teoria do trauma (Ferenczi, [1933] 1992).

\section{Algumas consideraçôes sobre Ferenczi, Abraham e ToroK}

A obra de Ferenczi é uma importante referência para o avanço desses temas, à medida que oferece um rico universo de reflexão sobre determinadas modalidades de sofrimento não circunscritas ao paradigma da histeria. $\mathrm{O}$ trauma ferencziano ${ }^{3}$ retrata um modo peculiar de subjetivação cujo enfoque abriu importante campo de investigação sobre a melancolia na obra de Torok. 
Torok dá uma dimensão teoricamente mais abrangente e clinicamente mais específica à teoria do trauma de Ferenczi, principalmente no que tange à temática da identificação. A autora articula o universo conceitual da identificação com o agressor e da clivagem, descritas pelo mestre húngaro, com seu próprio conceito de incorporação. Segundo Torok, a incorporação, ao contrário da noção ferencziana de introjeção, está na base da experiência melancólica. A incorporação se apresenta na subjetividade como algo que, ligado à experiência traumática, fica impossibilitado de se incluir, de se articular psiquicamente, manifestando-se de forma maciça, sem inscrição numa cadeia associativa. A fantasia da incorporação é, segundo Abraham e Torok ([1972] 1995), uma recusa da introjeção. Ao invés de introjetar ${ }^{4}$ o objeto perdido, através da atribuição de sentido com consequente metaforização (característica do universo polissêmico), há uma incorporação maciça desse objeto (hostil), por fantasia. Ocorre algo análogo a um enquistamento do objeto no psiquismo.

Este é o caso apenas para as perdas [narcísicas] que não podem - por alguma razão - se confessar enquanto perdas. [...] Todas as palavras que não puderam ser ditas, todas as cenas que não puderam ser rememoradas, todas as lágrimas que não puderam ser vertidas serão engolidas, assim como, ao mesmo tempo, o traumatismo, causa da perda. Engolidos e postos em conserva. O luto indizível instaura no interior do sujeito uma sepultura secreta (Abraham $\&$ Torok, [1972] 1995: 249; grifo nosso).

A ideia de incorporação em Torok é extremamente relevante para se pensar a subjetividade melancólica. Na melancolia pode-se perceber uma dificuldade profunda na subjetivação da própria existência. O sentimento de existência de si mesmo tornase extremamente frágil perante a onipotência do outro incorporado na identificação narcísica. No mesmo traçado teórico do conceito de clivagem em Ferenczi, e de incorporação em Torok, pode-se conceber na melancolia a ideia de uma não-inscrição psíquica da perda do objeto perante a fragilidade narcísica do melancólico, permanecendo o objeto clivado dentro do próprio eu (cf. Verztman, 2002).

\section{LAMBOTTE E O DISCURSO MELANCÓLICO}

Outra autora que pensa a melancolia de maneira aprofundada é Marie-Claude Lambotte. Na obra $O$ discurso melancólico, Lambotte (1997) oferece um rico universo de reflexão sobre as complexidades melancólicas relacionadas ao campo do 
narcisismo. A autora aponta para uma relação peculiar na formação da imagem de si do melancólico, o qual seria incapaz de aceder a um estatuto de preenchimento ideacional narcísico, característico dos pacientes neuróticos.

Em outras palavras, Lambotte demonstra que o trauma, situado num momento pré-especular, introduz uma condição a partir da qual não ocorre um sentimento de existência de si. Para Lambotte, esta configuração caracteriza-se como um "desmentido de existência" no campo do sujeito. A mãe fracassa em seu investimento, e não mantém para o mesmo a subjetivação de sua própria existência. Segundo a autora, o olhar da mãe não atingiu o sujeito ao ponto de este forjar para si uma autoimagem capaz de desfrutar de um amor de si de tipo jubilatório.

Nesses termos, se a autodepreciação parece ser uma das mais importantes características do discurso melancólico, Lambotte dirá que esta se apresenta apenas como problema secundário. A autora aponta que a incerteza de si só poderá ser ultrapassada se for substituída por um desvelamento absoluto do enigma da morte; elemento utilizado constantemente pelo melancólico para sustentar sua própria referência discursiva.

A morte é uma referência central do discurso melancólico, o qual passa a girar em torno da crueza das coisas e da crueldade da finitude. Esses sujeitos postulam a si mesmos como detentores fiéis da verdade trágica da morte, tornando-se dela seus maiores aliados. Atiram-se vertiginosamente em direção a ela como que numa apropriação radical da verdade, da qual os outros seres humanos tentam desviar-se em suas "inúteis ilusões".

A certeza de sua miserabilidade, revestida de autotirania e culpabilidade, aponta em última instância - e esta é uma das mais importantes constatações de Lambotte - para uma busca das origens de si mesmo jamais encontrada. Nessa circunstância, o sujeito, atirado ao limbo de sua própria existência, não se reconhece nem atribui a si algo de consistente. Nesses casos, Lambotte (1997: 157) afirma que: "[...] aquém da autodepreciação tão frequentemente designada como uma das características essenciais da atitude melancólica, é a questão das origens que a acossa permanentemente, como o desconhecido de uma equação para a qual se tentaria achar as variáveis pertinentes".

A autora trabalha com a hipótese de que a aniquilação de si está diretamente relacionada a problemas na própria constituição do narcisismo em função de o olhar do outro (mãe) não ter preenchido a circunscrição imaginária do corpo. A mãe aparece no discurso melancólico quase sempre como toda-potente, objeto absoluto que, com seu olhar, circunscreve a silhueta corporal da criança, emprestando a ela a possibilidade de formação de um esquema corporal. Este esquema, contudo, é desinvestido da libido que lhe poderia garantir um preenchimento narcísico e um 
sentimento positivado de existência no discurso do outro. Nessa perspectiva, a mãe, toda-potente, lançaria sobre a criança um discurso sem atribuições ou investimentos, asseverando apenas uma existência pontual e descontínua, o que constitui o cerne do trauma e da ambivalência melancólica.

O olhar materno não circunscreve o que viria a ser um futuro sujeito, produzindo, por outro lado, uma deserção de desejo (Lambotte, 2001). Desejo do Outro que, desertado, não inclui o sujeito na dinâmica da pluralidade identificatória, isto o levando a um vazio sem precedentes, que caracteriza precisamente uma identificação ao nada (cf. Lambotte, 2001).

Com efeito, na melancolia o eu não se precipita mediante a ilusão de sua própria onipotência. Se há onipotência na melancolia, esta se configura por um discurso enquistado, clivado. $\mathrm{O}$ discurso onipotente do outro assume uma configuração negativizada, produzindo um sujeito identificado ao nada. $\mathrm{O}$ sentido da onipotência fica enquistado, isolado de qualquer referência narcísica ou representação de si mesmo. O discurso melancólico apela para uma existência no nada e revela uma única saída no simbólico - "eu não sou nada", frase que caracteriza a construção narrativa por excelência desses sujeitos (cf. Lambotte, 2001).

Aqui, delineiam-se os primeiros passos para uma distinção entre a constituição melancólica e a formação ideal dos pacientes deprimidos não-melancólicos. Nessa linha, o enfoque para uma análise dessas questôes encontra sua principal referência na dimensão narcísica, cuja crença aparece como balizador.

Passemos ao estudo da depressão e sua especificidade mediante uma análise sobre a noção de crença narcísica, elemento teórico fundamental para a abordagem da depressão tal como a concebemos a partir da pesquisa teórico-clínica.

\section{A CRENÇA NARCÍSICA}

A noção de crença narcísica é aqui postulada para descrever determinadas formas de o sujeito situar-se perante a perda. Ela revela um tipo de organização narcísica que toma como referência o sentido de onipotência do eu conflagrado pelo investimento do outro parental na constituição do sujeito.

Para abordar esse tema, tomamos como referência a noção de crença no pensamento pragmático de William James e Richard Rorty. A crença, tal como a entendemos a partir desses autores, acha-se correlacionada ao aspecto linguístico da experiência, constituindo um dos principais elementos do processo de subjetivação à medida que a linguagem assume lugar decisivo no jogo das ações humanas. William James ([1907] 2005) argumenta que toda ação se acha sustentada por 
uma crença ou um conjunto de crenças que fundam sujeito e realidade em seus aspectos físico, psíquico e social. $\mathrm{Na}$ mesma linha de pensamento, e referenciado no pragmatismo linguístico, Rorty (1997) sustenta que toda ação acha-se subjugada aos jogos de linguagem, que situam um sujeito num determinado contexto. Nessa acepção, a crença é entendida como uma regra para a ação, o que define o campo da ação como resultado de um jogo de crenças articuladas na relação do sujeito com a realidade (James, [1907] 2005).

Do ponto de vista subjetivo, a crença participa decisivamente da formação do sujeito. Esta pode ser característica do universo infantil, quando, por exemplo, o outro parental imprime sobre a criança seus próprios anseios narcísicos perdidos (Freud, [1914] 1996). Esse universo de sentidos plurais sobre o lugar privilegiado que a criança passa a assumir na idealização e no hiperinvestimento dos pais é o que inaugura a experiência da crença narcísica. Essa experiência caracteriza-se como o efeito subjetivo de um discurso idealizado. Um discurso sumariamente condicionado pelo sentimento de desamparo dos próprios pais, quando estes colocam em suspenso a fragilidade de suas próprias vidas através do novo ser que chega. Com efeito, o traço relacionado à experiência de um eu consistente é resultado da interpretação do discurso do outro por parte desse novo aparelho psíquico que se forma. $\mathrm{O}$ qual não pode ter lugar fora do âmbito dos atos linguísticos sustentados num a posteriori de idealização. A experiência de um investimento narcísico pleno e absoluto é, portanto, um momento mítico. Neste, o sujeito só-depois se referencia como tendo outrora desfrutado de uma posição de onipotência no discurso dos pais.

Nessa direção, entende-se o estatuto da crença narcísica como uma resposta à instabilidade que toma como apoio o discurso idealizado do outro, forjando-se, assim, a sensação de uma onipotência do eu. É um movimento psíquico relacionado ao sentimento de desamparo do outro, um ato interpretativo subjacente à demanda de completude do outro inserido na cultura - demanda remetida ao constante desejo de ser amado e reconhecido.

A crença narcísica é efeito mesmo de um desencontro que subjaz à necessidade de sobrepujar e de burlar a impermanência. Em tais circunstâncias, a visada psíquica em questão é a de manter uma estase, agora condicionada pela idealização do investimento dos pais caracterizado pela fórmula "Sua Majestade o Bebê". É precisamente no (des)encontro com o outro que se formarão os ideais, cuja referência é a articulação de um sentido: o sentido da onipotência. Nesse patamar, se a crença narcísica é uma crença na onipotência e na unidade, esta crença pode apenas ser condicionada na relação com o outro que participa diretamente da invenção subjetiva do infante. 
Esta apreensão se acha na base de toda uma conjuntura circunscrita ao problema da perda no campo do sujeito. Na situação específica da crença narcísica, assumir hegemonia na hierarquia de crenças de um dado sujeito. Ela funciona como uma defesa perante a experiência da perda. Com efeito, a crença narcísica, que conjuga o sentido da imortalidade do eu com o de sua onipotência, não comporta a ideia de finitude. Como veremos, sua presença hegemônica na vida psíquica impõe uma condição paradoxal. Coloca o sujeito na contramão de sua capacidade de ação. È exatamente um movimento deste tipo que supomos estar na base da vivência depressiva contemporânea, tornando-a tão distinta do luto e da melancolia.

\section{Circunscrição ConCEITUAL dA DEPREsSÃo}

Ao iniciar esta seção, devemos nos desvencilhar de alguns problemas conceituais. Em primeiro lugar, não estamos em posição de conferir à depressão um estatuto nosológico no campo psicanalítico. Entendemos que este caminho a colocaria numa dimensão isolada de outras afecções relativas à sua configuração sintomática. Deixamos assinalado que a depressão configura-se como um estado que pode se manifestar em várias organizações psíquicas. Neste traçado teórico, damos destaque a um tipo específico de depressão que se manifesta cada vez mais nos dias de hoje e que está próxima do campo da neurose. Diferentemente da melancolia - e não menos das depressões histérica e obsessiva -, nossa hipótese é de que esse tipo de depressão é uma das mais importantes vicissitudes da crença narcísica atualmente, deflagrando um estado psíquico peculiar quando da incidência de uma perda objetal.

A clínica tem trazido inquietantes manifestações subjetivas face à questão da transitoriedade. A depressão revela que o sujeito, predominantemente referenciado nas vicissitudes de sua crença narcísica, desfalece num sofrimento, marcado pela dificuldade de elaborar sua própria condição transitória. Essas depressões, referenciadas num apelo narcísico ideal, acirram-se na contemporaneidade como forma peculiar de defesa perante a perda e o desejo. Elas deflagram novas formas de resposta aos impasses da onipotência narcísica e da emergência de uma imagem de si impedida de metaforização.

O deprimido referencia-se a si mesmo como se ele coincidisse com uma imagem parada, bidimensional, à qual falta movimentação afetiva. Esta forma de negação do desejo (e da perda) apresenta-se, na contemporaneidade, como mais poderosa e radical do que na histeria e na neurose obsessiva, as quais fracassam em 
seus movimentos defensivos. Não se trata, nesse tipo de depressão, de um sentimento vago de tristeza "sem se saber por quê", como ocorre por vezes na histeria. Esses pacientes sabem o que os aflige, sabem o que está perdido (Pinheiro, 2005). Algo revela para o sujeito uma desgraça já materializada, sem que haja qualquer possibilidade aparente de mudança.

A experiência depressiva toma como referência uma imagem centralizada de si, colada às insígnias do narcisismo infantil (Sua Majestade o Bebê). Referenciados num sentimento profundo de perda, esses pacientes falam de uma perda da referência narcísica, outrora desfrutada como insígnia de uma condição ideal impedida de transformação.

Diferentemente dos pacientes melancólicos, que não apresentam qualquer referência a uma experiência jubilosa no narcisismo, os pacientes deprimidos fazem referência ao júbilo da imagem de si subjugados à idealização do outro parental. Entretanto, permanecem radicalmente atados à crença narcísica e encontram grandes dificuldades em estabelecer uma projeção de si no futuro. Eles projetam (apenas para o passado) um eu-ideal forjado na configuração familiar do discurso dos pais, contudo sumariamente perdido. É uma imagem de si que, como eles mesmos sabem, nunca será recuperada ou alcançada.

Nesses termos, o deprimido, diferentemente do melancólico, afirmou-se como existente, mas não inscreve as transformaçôes inerentes à vida e à temporalidade. Ele toma o objeto como condição necessária em torno da qual o sujeito mantém sua alienação. O deprimido, diferentemente do melancólico, foi fisgado pelo desejo (Pinheiro, 2005). Contudo, atado à crença narcísica, ele instaura para si uma denegação que revela desejo e finitude como duas pontas do mesmo fio.

Podemos reconhecer esta forma de sofrimento na obra literária de Tchekhov - Ivanov (Saceanu, 2004) $)^{5}$ - anteriormente mencionada. Ivanov, personagem principal da obra, fala de uma imagem de si perdida e impedida de transformação no tempo. Este personagem apresenta um discurso que se debruça sobre um eu-ideal irrecuperável, tal como um ego que pranteia sua própria ruína narcísica ${ }^{6}$. Não se trata de um desmoronamento narcísico como na melancolia, mas, precisamente, de uma nostalgia que retira o sujeito de sua capacidade de transformação e metaforização. É uma história fixa, cuja narrativa não cessa de recair sobre ela mesma, não restando ao sujeito outra coisa senão deprimir ante a imagem narcísica perdida.

No último ato da peça, Ivanov se nega a relançar-se ao desejo e ao novo. Faz isso, dizendo à Sacha (sua noiva) que não pode se casar por causa da prova que o tempo outorgou como impeditivo de união com ela. Diz que não conseguiria recuperar o vigor perdido ante aos cabelos brancos que viu pouco antes da cerimônia de casamento. Ao deparar-se com sua imagem no espelho e com a marca 
da temporalidade, a personagem desiste não apenas de seu casamento, mas de qualquer movimento desejante. Ivanov sofre violentamente por seu passado não fazer elo entre ele e seu presente.

Sua fala representa o cerne do discurso depressivo, que remete apenas a uma imagem de si perdida num passado irretocável. Em Ivanov destaca-se sua lamúria pela perda de entusiasmo e investimento, bem como pela ausência definitiva de sua imagem jovial de outrora. Sublinha-se que a depressão e o subsequente suicídio de Ivanov sobrevêm do desligamento entre a imagem de si no passado, no presente e no futuro - ligação que suportaria o tempo de espera e a sustentação do desejo. Como esclarece um de nós (Pinheiro, 2005: 104): "Se o sujeito só dispõe da imagem do presente e uma imagem de si no futuro, mas não dispõe de uma narrativa que articule um flash com o outro, seu desejo está fadado a não se realizar e só lhe resta deprimir". E se conclui: "Na depressão é possível às vezes esboçar um desejo que rapidamente se esvanece" (Pinheiro, 2005: 104).

Há aí um corte subjetivo violento, subjacente a uma imagem de si incapaz de reaparecer transformada no tempo. Conforme se constata a partir dos estudos clínicos, esses pacientes não elaboram, numa construção narrativa, a condição da transitoriedade.

Ressalta-se, nesse âmbito, que, se a crença narcísica é radical e intransponível, o eu pode apenas aparecer como perdido e impossibilitado de transformação. A única forma de sustentação discursiva passa a ser a centralização no ego-ideal perdido. Nessa condição, o sujeito subtrai-se de sua condição desejante e deprime violentamente. Os pacientes característicos desta configuração subjetiva não fizeram o luto de sua perda narcísica. Portanto, resta apenas o naufrágio do desejo e o afogamento de si na imagem perdida do eu-ideal irrepreensível. A obra de Tchekhov ilustra o que nessas depressões aparece como trágico. A nova imagem de Ivanov no espelho não é subjetivamente atualizada, não sendo integrada a uma nova rede de crenças; ela funciona como trauma, num desligamento psíquico e numa irrupção pulsional cuja violência culmina no ato do suicídio.

A figuração literária de Ivanov serve como exemplo para se pensar essas modalidades depressivas que se diferenciam tanto da melancolia como das depressóes histéricas e obsessivas. Na histeria, a negação do desejo fracassa e o sujeito se mantém, ainda que sintomaticamente, no circuito desejante. $\mathrm{O}$ retorno do recalcado, tanto na histeria quanto na neurose obsessiva, são marcas desse fracasso a partir do qual o sujeito constrói uma circunstância sofrida como expressão de um dizer inconsciente sobre o desejo.

Como se verifica na histeria, o sintoma representa o laço desejante com o outro que, figurado pela posição de um pai claudicante, situa para o sujeito a con- 
dição de insatisfação permanente perante o objeto sempre em falta. Já na neurose obsessiva, o sujeito se encontra, sumariamente, submetido ao ideal de eu paterno e à ambivalência depressiva resultante da perda do objeto, como assevera Freud ([1917] 1996). O autor faz referência precisamente a tal submetimento simbólico. É nesse sentido, que a culpa pelo ódio ao pai constitui o cerne da esfera sintomática articulada pelo temor do superego na obsessão, sobrepujando-se aí o deslocamento sintomático como índice do fracasso defensivo.

$\mathrm{Na}$ depressão contemporânea, a negação do desejo é radical e bem-sucedida, e o sujeito acha-se fadado à sua própria estagnação. Como sugerimos, Ivanov representa, no momento atual da investigação psicanalítica, o paradigma desse fenômeno depressivo próprio da contemporaneidade.

Mediante análise acerca da relação entre a crença narcísica, o luto e a finitude nessas formas de sofrimento, é importante frisar que o enigma da morte, que se apresenta para esses pacientes como efeito da perda inevitável, assume o destino vil de sua antecipação. Por não encontrarem espaço psíquico para a construção de novas vias desejantes, distintas da crença narcísica, os pacientes deprimidos atiram-se terminantemente à repetição e à mortificação.

A depressão aguda constitui, em sua própria radicalidade, a segunda face de uma mesma moeda: onipotência narcísica e estase depressiva. Eis, portanto, o cerne da questão que articula crença narcísica e depressão. A depressão é um efeito da não-destituição da crença narcísica, esta última proporcionada pela instauração do ideal do eu. É a superestimação do eu ideal, subjacente ao sentido de onipotência narcísica (expressão "primária" da estase jubilosa), que precisamente estabelece tal ordem de coisas inerentes a "Sua Majestade o Bebê". Diante da perda, o "ego infantil”, forjado pela crença da onipotência e da unidade narcísica, depara-se com um impasse cuja saída vai definir a rota pela qual o sujeito trilhará seu caminho.

Frisa-se nesse contexto, a partir do pensamento de Freud, que a abertura ao jogo da vida e do desejo exige que o sujeito inscreva-se como transitório, mutável, descentrado e mortal. É certo que Freud foi o primeiro a apontar, de maneira genial, o caráter dramático destes paradoxos com a figuração de "Sua majestade o Bebê" (Freud, [1914] 1996), na qual mostrou a não-sobriedade do credo infantil. E esta reflexão culminará em sua análise sobre a questão da finitude na esfera subjetiva que se encontra no texto "Sobre a transitoriedade" ([1915] 1996).

Nesses termos, situamos o estado depressivo grave como resultado vil da negação do desejo e não menos da finitude. Ou seja, o mito narcísico da onipotência e da imortalidade não passa de um lampejo de perfeição que se apaga no tempo, mas cuja finitude, se não é elaborada numa construção narrativa, reduz o sujeito, paradoxalmente, a um natimorto. 
A depressão, como primeira voz da crença narcísica, é o último refúgio para o arrefecimento da perda. A estagnação depressiva (e seu sofrimento intrínseco) é, portanto, a via pela qual o sujeito nega a morte de seu narcisismo, além da própria transformação subjetiva que ela proporciona mediante a inserção no circuito desejante.

O sujeito é convocado, na trama da cena narcísica e da perda objetal, a reposicionar-se perante a finitude. Nessa circunstância, o deprimido parece encapsularse nos subterfúgios da crença narcísica, a qual, em sua face de estase depressiva, sinaliza a busca pelo retorno da onipotência do eu - ainda que num movimento inverso de silenciamento absoluto e denegação radical do descentramento de si. É a contrapartida oposta àquela subjacente à ação e ao desejo, sendo o luto o principal balizador desta conjugação entre a morte e a vida.

\section{A DEPRESSÃo E SUA ESPECIFICIDAdE FRENTE AO LUTO E À MELANCOLIA}

Propomos uma relação de heterogeneidade não apenas entre o luto e a melancolia - como aponta Freud -, mas também entre o luto e a depressão. O luto é justamente um movimento de elaboração psíquica da perda, não restando a este conceito outra apreensão que não seja a de afastamento da cronicidade depressiva. Portanto, não há luto na depressão. Não há, tampouco, um luto patológico que seria um desvio de norma do luto. É como se na depressão o luto existisse como referência a uma transcendência, que contivesse em si mesmo um conjunto de elementos tomados a priori - um juízo de valor sobre "certo e errado" - do qual a psicanálise tende a se afastar. Nesse contexto, é preciso conceber o luto como uma forma que o homem civilizado tem encontrado para lidar com a questão da finitude, do trauma, da perda e da morte.

O luto tem como função, de acordo com Freud, (re)inserir o sujeito no circuito desejante. É um trabalho de ligação e integração daquilo que solapa o sujeito e fica, momentaneamente, sem construção narrativa. Ele aparece como mola propulsora da simbolização e elaboração narrativa da perda, mediante reconstrução da dor psíquica. Em outras palavras, o luto tem por função matar o morto, dando a ele um lugar simbólico subjacente à elaboração, também simbólica, da perda.

O luto, como insígnia da elaboração psíquica da perda, constitui um doloroso caminho percorrido a fim de assimilar a transitoriedade da vida e metaforizar seu desejo. Por outro lado, além de proporcionar tal assimilação simbólica, o enlutado se protege de seu próprio desmoronamento mediante um momento passageiro de 
acirramento da dor psíquica - a lembrança do objeto perdido, o pranteamento, a inibição passageira etc. Essa evitação do desmoronamento narcísico é exatamente o que o melancólico, marcado pela precariedade de sua formação narcísica (cf. Lambotte, 1997), não consegue efetuar.

$\mathrm{Na}$ melancolia, como vimos, há um desmentido da perda, assim como da renúncia ao objeto. O melancólico não pode perder o objeto ao qual se rendia, visto que nele o sujeito encontrava sua única forma - ainda que extremamente frágil - de continuidade do próprio sentimento de existência. Nessa circunstância, o sujeito, identificado ao vazio deixado pelo outro, entra num conflito de forças que revela a precariedade narcísica e o risco de seu desmoronamento.

Esta faceta é inerente ao problema da melancolia relacionado à constituição do eu e do objeto. Como ficou frisado, a não-inscrição psíquica da perda objetal revela que o objeto sequer chegou a tomar uma circunscrição na subjetivação melancólica. Nessa condição, o sujeito se desfacela e é absorvido pelo objeto in toto. Não há, para o melancólico, registro simbólico da perda objetal pelo fato mesmo de que a deserção do Outro assinala, na constituição do sujeito, sua própria identificação ao nada.

Sobre essa questão, Freud ([1917] 1996) sublinha que, na melancolia, o que se perdeu foi o ego. Justamente porque esta perda diz respeito ao próprio movimento constitutivo da imagem ideal de si no narcisismo primário que fracassou. $\mathrm{O}$ ego perdido refere-se, na melancolia, à identificação ao nada. Nessa condição, o objeto não se constitui como perdido. Se, no surto melancólico, "o que se perdeu foi o ego", é porque - Freud o diz - a sombra do objeto o consumiu, tomou seu lugar - que era, precisamente, uma referência no nada. O melancólico, como demonstramos, nunca desfrutou de uma imagem jubilosa de si. Nunca lançou-se ao enamoramento narcísico condicionado pelo discurso idealizado dos pais. A barreira para a enunciação mesma de um "eu" positivado, cuja narrativa construiria esta possibilidade, levanta-se, paradoxalmente, como tentativa nunca alcançada de construção do sentimento de si na melancolia.

Mostra-se relevante situar, no contexto da relação com a experiência narcísica, as diferenças entre o modelo melancólico stricto sensu e as depressões nãomelancólicas, discutidas neste trabalho. Com efeito, o discurso da perda de si na depressão ganha contornos próprios que diferem da "perda do eu" na melancolia, conforme indicou Freud.

O deprimido, diferentemente do melancólico, protesta contra a perda. Não se permite lançar-se a novas possibilidades de investimento objetal. Há na depressão um registro psíquico da perda. $\mathrm{O}$ deprimido martiriza-se por ela e sabe o que ficou perdido. Por isso mesmo não há retorno do objeto sobre o eu, dado que o 
deprimido foi fisgado pelo investimento dos pais e pela formação da imagem de si. O deprimido tece uma narrativa sobre a perda, contudo não encontra sustentação para sua elaboração.

Nesse patamar, constata-se que a transitoriedade é tão insuportável para o deprimido quanto é impossível a realização da crença narcísica. Tal como o melancólico, mas por razões diferentes, o deprimido não faz o trabalho do luto. A função de separação e elaboração da perda não é colocada a termo, visto que a crença narcísica, objeto por excelência do sofrimento depressivo, opera seu efeito sintomático. E, com isso, deflagra a inoperância do sujeito frente à perda, à transitoriedade e à exigência de trabalho psíquico próprio do circuito desejante. $\mathrm{O}$ deprimido é, portanto, um nostálgico absoluto. Sua rendição ao narcisismo é de tal espécie que ele nega qualquer possibilidade outra que não seja aquela conflagrada pela crença narcísica.

Nas depressões agudas não-melancólicas, o discurso é de uma perda de si. Mas, ao contrário da melancolia, é o discurso sobre a perda de uma imagem perfeita subjugada pelo assombro de sua própria transitoriedade. Não se encontra a ambivalência, a clivagem do eu; tampouco o conflito que sinaliza a fragilidade do ego melancólico e a identificação com o objeto. Nessas depressões não-melancólicas, portanto, o sujeito pranteia $o$ que foi, numa reinvindicação fixa de seu próprio modelo narcísico ideal.

Aqui, o sintoma diz respeito a uma aderência à crença narcísica perdida ou crença num absoluto, da qual o sujeito não consegue abrir mão. Subsumida a um anseio de indiferenciação eu / outro, a crença narcísica é sedução do mito maternal (eu-ideal), chave da satisfação sumária de todas as urgências infantis. Anseio que não pode ser realizado, mas pode ser forjado pela via do gozo depressivo. Nele, o sujeito encontra alguma forma de degustar a estase narcísica perdida, ainda que pelo sabor amargo da indiferença afetiva.

O deprimido em sua amargura faz referência à imagem ideal perdida ("eu já fui e hoje não sou mais"), como se, pela via da estagnação, o gozo da indiferença - e mesmo da onipotência - fosse recuperável ou mesmo possível. Portanto, na depressão, é como se o sujeito dissesse: "se não sou mais o que fui (em outras palavras, se não sou o todo da relação ego-ideal), não quero mais nada”. A queda ladeira abaixo é, contudo, vertiginosa. E se o sujeito não encontrou vias de elaboração da transitoriedade, numa narrativa capaz de relançá-lo a uma "reinvenção de si mesmo", corre o grave risco da aceleração de sua própria morte ${ }^{7}$.

Dado que na depressão a referência acha-se concentrada no eu-ideal, o que vai especificar a subjetivação dos pacientes deprimidos é uma peculiaridade na passagem do eu ideal para o ideal do eu. Centralizado na crença narcísica, o depri- 
mido é o próprio perdido de si mesmo. É um sujeito centrado na essência do eu, que somente a crença narcísica pode sustentar. Nessa perspectiva, o deprimido nega seu próprio descentramento por não aceitar o jugo da transitoriedade, da diferença e do desejo.

Com efeito, ante o fato de que o sujeito centraliza-se na imagem perdida, é a questão do ideal do eu (o qual sustenta a possibilidade de laço desejante e de movimentação objetal) que se acha comprometida. Esta circunstância se situa num nível em que a formação ego-ideal se firmou, mas fracassou em construir as vias de transformação, características da passagem do eu ideal para o ideal do eu.

Verifica-se, nesse âmbito, que o ideal do eu na depressão constitui-se numa precipitação do eu-ideal, a qual impede qualquer reconstrução da história subjetiva e, consequentemente, afastamento da crença. O que marca o sofrimento nessas depressões é a relação com um ideal do eu colado à imagem perdida de si mesmo. $\mathrm{O}$ ideal do eu se confunde com o eu ideal, fica colado a uma dimensão de passado que não faz link com o futuro.

Nesses termos, o que é colocado no lugar do ideal do eu não é a figura do Pai tal como Freud ([1923] 1996) descreve no drama edipiano. Preso e dependente de sua única referência aparente - a crença narcísica -, o sujeito coloca no lugar do ideal do eu o próprio eu ideal perdido. O sujeito, aqui, está inscrito minimamente numa triangulação objetal, mas eximido de uma referência assimétrica capaz de sustentar um ideal no qual poderia se apoiar e abrir mão de sua própria imagem narcísica. Ele se vê na condição peremptória de construir sozinho, e para si mesmo, seus próprios valores e seus próprios ideais.

\section{CONSIDERAÇÕES SOBRE A DEPRESSÃO E SUAS IMPLICAÇÕES FACE AO CONTEXTO CONTEMPORÂNEO}

As pesquisas do NEPECC desenvolvem, atualmente, estudos voltados para determinados tipos de sofrimento que preponderam na contemporaneidade, que constituem novas formas de o sujeito lidar com questôes relacionadas ao tempo, à finitude è̀s exigências da cultura. Constata-se, nesse âmbito, que a crença narcísica aparece hoje, muitas vezes, como via privilegiada de relação com o outro, bem como de organização no mundo - deflagrando, assim, a depressão como um dos principais signos do sofrimento psíquico na contemporaneidade.

No que diz respeito à dimensão do tempo na contemporaneidade, percebe-se que este é um importante elemento de distinção entre depressão e luto. O luto é um processo psíquico que sinaliza a inscrição do sujeito no tempo - um tempo 
que se inscreve como "escasso" - a partir do qual o sujeito coloca-se na condição de agir e desejar para além da idealização. Se afirmamos que na depressão não há trabalho de luto, é porque nela há uma destinação peculiar à dor da perda, ou ao fracasso da projeção ideal.

O sujeito contemporâneo encontra grandes dificuldades de ligar presente e futuro num processo psíquico de integração que o filiaria, no caso do luto, a uma ação descolada da idealização. O que se verifica no discurso dos pacientes deprimidos é a projeção no futuro de um eu ideal, impossível de se realizar - e, isso, quando há uma projeção no futuro. Sem estabelecimento de qualquer construção narrativa a partir da qual o sujeito dispor-se-ia a agir, a idealização de si mesmo no futuro é similar à própria idealização de "Sua Majestade o Bebê". Ela é de tal ordem que o sujeito deprime como expressão do fracasso de seu ideal narcísico. A imagem de si no presente é sempre insuficiente perante a exigência do eu-ideal "absoluto" e "perdido". O deprimido situa-se num flash, num tempo instantâneo, que liga diretamente presente e futuro, sem constituir um tempo de ação no sentido da realização, ou um tempo de espera (tempo do desejo), cujo processo psíquico, de outra sorte, integraria presente e futuro, numa "costura" entre dois momentos.

O tempo desses pacientes é o puro tempo presente. É o tempo do imediato, do instantâneo, da pressa, da satisfação absoluta e, portanto, da crença narcísica. Nesse sentido, sinaliza-se, aqui, uma forma de subjetivação que faz do tempo uma estagnação do eterno presente, no qual o "passado perdido" torna-se instantaneamente o "futuro inalcançável". Nessa circunstância, não aparecem referências a um ideal do eu que sustente a transformação subjetiva no tempo. O que prevalece é, no máximo, um eu ideal lançado como possibilidade única de existência no mundo psíquico. Perante as mudanças da imagem de si no tempo, subjugadas à insustentabilidade do ideal narcísico, sobrevém o sintoma depressivo figurado anteriormente pela obra de Tchecov (Ivanov).

A abordagem sobre esse modo de sofrimento concebe, assim, uma forma peculiar de relação com o tempo, fator crucial de diferenciação acerca do próprio trabalho do luto, como salientamos. O luto é, como dissemos, um trabalho ou processo psíquico. Ele se realiza dentro de um tempo que tem como resultante a identificação por traços com uma modificação no eu - sustentada pelo ideal do eu (Freud, [1923] 1996) - que funciona como balizador do desejo. Esta condição é o que conduz o sujeito a uma reinserção desejante e à reconstrução da capacidade de ação, segundo Freud ([1923] 1996).

De outra via, é o tempo da pressa contemporânea que acirra os modos de satisfação não mediados pelo desejo. Hoje, a negação do tempo da espera e da ação se acirra numa cultura em que a norma é agir. Agir no sentido de uma performance 
muitas vezes inalcançável por ser imediata em sua própria exigência. Esta norma da ação, no mundo contemporâneo, exige do sujeito uma eficácia individual imediata que confira o status de sua posição socioeconômica. Tal exigência de performance configura o que Ehrenberg (1998) considera como uma mudança na forma de subjetivação no cenário atual. $\mathrm{O}$ autor afirma que o mais significativo nessa conjuntura é a substituição de questões ligadas à interdição, à identificação simbólica e à falta por questôes que envolvem a perda de objeto e a identidade narcísica (imaginária). Aqui, Ehrenberg situa que, exigidos constantemente no sentido de uma performance irrestrita, esses sujeitos parecem prisioneiros de um eterno presente. Nessa prisão da performance, cada vez mais inalcançável, o sujeito deprime como expressão radical de sua dificuldade de agir.

A busca pelo imediatismo no campo da satisfação e pela perfeição imagética traduz a face mais radical dos discursos atuais. Em sua configuração, a técnica e o desempenho visam, dentre outras coisas, à supressão da finitude. A cultura atual parece buscar o adiamento, ou mesmo dissipação, da morte mediante os insidiosos poderes tecnológicos numa suposição de que abrir mão da ideia de degradação intrínseca à vida seja possível. A cultura contemporânea enuncia em suas entrelinhas uma nova negação da finitude. Nesse contexto, a morte poderia ser supostamente suplantada com a garantia prometida dos avanços tecnológicos a partir dos quais o mundo hoje se organiza (Ehrenberg, 1998). A nova salvação para a finitude centralizar-se-ia no aparato tecnológico, o qual se associa terminantemente à perseguição narcísica do bem-estar e da satisfação imediata, bem como da autoimagem perfeita e não atingida pelo tempo.

Esta conjuntura faz do desejo algo ainda mais insuportável na contemporaneidade. E coloca o sujeito numa condição de silenciamento frente aos percalços da perda e da finitude. A crença narcísica aparece na contemporaneidade como protagonista dessas modalidades discursivas, não implicando o sujeito na construção do ideal do eu e no subsequente afastamento da crença narcísica.

Constata-se que as formas de subjetivação na atualidade diferenciam-se daquelas investigadas por Freud. Ali, se tinha a instauração bem definida do ideal do eu como prevalência de uma imago "superior" que define os valores, as crenças e os ideais a serem alcançados - sustentando a coesão, tanto grupal quanto psíquica (Freud, [1923] 1996). Na cultura atual esses modelos simbólicos parecem declinar, instaurando de maneira mais radical o sentimento de desamparo. Como apontam Herzog e Pinheiro (2003:42), trata-se de: "Transformações que incidem sobre o modo como se organiza o socius e cujo efeito maior se mostra no colapso das convençôes coletivas, provocando um esfacelamento da autoridade simbólica. Somos lançados assim numa era de incertezas uma vez que perdemos toda a garantia de uma referência”. 
Tais especificidades surgem quando nos deparamos, na clínica atual, com formas de sofrimento que nos levam a pensar um modo peculiar de reação à perda. Esta que faz parte da dinâmica depressiva, na contemporaneidade, face aos efeitos da crença narcísica. Esta questão se intensifica num mundo em que a fragilidade perante a finitude e a temporalidade aparece como signo radical de negação do desejo.

\section{CONCLUSŌES}

O objetivo desta exposição foi alcançar as vias de circunscrição da subjetividade depressiva contemporânea frente ao luto e à melancolia. Como afirmamos, estamos tomando a depressão como um estado, não como uma entidade diagnóstica em psicanálise. A depressão aqui descrita revela especificamente que, por razões ainda pouco conhecidas em âmbito teórico, as questōes que envolvem o mundo contemporâneo parecem empurrar a neurose para dimensóes narcísicas de maneira muito mais acentuada do que se faz notar a partir do drama edipiano. Esta conjuntura convoca o sujeito de forma imperativa, como frisamos acima, a construir seus próprios valores e ideais, fora de uma referência sustentada por uma assimetria subjetiva, característica do ideal do eu.

De fato, é importante salientar a forte incidência na clínica atual de depressões desse tipo. $\mathrm{O}$ que exige destaque equânime às formas de se responder, na atualidade, aos percalços da perda. Assim, identificamos nessas depressões uma forma específica de defesa ante a perda. Uma maneira distinta de negá-la, ou de não renunciar ao objeto. A depressão é, pois, uma forma contemporânea de negação do desejo, um sintoma da contemporaneidade.

Se o luto é um processo psíquico que promove a renúncia ao objeto, se na melancolia o sujeito identifica-se narcisicamente ao objeto perdido e se a depressão é uma defesa bem-sucedida em relação ao desejo, concluímos que luto, depressão e melancolia são, da maneira como foram abordadas, três formas heterogêneas de reação à perda detectadas pela clínica psicanalítica. Esta revela, sem dúvida, modos de subjetivação e sofrimento que exigem de nós um constante redimensionamento teórico acerca dos contextos clínicos que se impóem na atualidade.

\section{REFERÊNCIAS}

Abraham, N. \& Torok, M. (1972). A casca e o núcleo. São Paulo: Escuta, 1995. Ehrenberg. A. (1998). La fatigue d'être soi: dépression et société. Paris: Odile Jacob. 
Ferenczi, S. (1912/1992). O conceito de introjeção. Psicanálise I. São Paulo: Martins Fontes.

Ferenczi, S. (1933/1992). Confusão de língua entre os adultos e a criança. Psicanálise IV. São Paulo: Martins Fontes.

Freud, S. (1913/1996). Totem e tabu. Obras completas, ESB, v. XIII. Rio de Janeiro: Imago. Freud, S. (1914/1996). Introdução ao narcisismo. Obras completas, ESB, v. XIV. Rio de Janeiro: Imago.

Freud, S. (1915/1996). Sobre a transitoriedade. Obras completas, ESB, v. XV. Rio de Janeiro: Imago.

Freud, S. (1917/1996). Luto e melancolia. Obras completas, ESB, v. XV. Rio de Janeiro: Imago.

Freud, S. (1923/1996). O ego e o id. Obras completas, ESB, v. XIX. Rio de Janeiro: Imago. Herzog, R. \& Pinheiro, T. (2003). Impasses na clínica psicanalítica: a invenção da subjetividade. Estados Gerais da Psicanálise: Segundo Encontro Mundial, Rio de Janeiro.

James. W. (1907/2005). Pragmatismo. São Paulo: Martin Claret.

Lambotte, M. C. (1997). O discurso melancólico - da fenomenologia à metapsicologia. Rio de Janeiro: Companhia de Freud.

Lambotte, M. C. (2001). A deserção do Outro. Revista da associação psicanalítica de porto alegre. Absorveu: Boletim da Associação Psicanalítica de Porto Alegre: APPOA, 20, 84-101.

Pinheiro, T. (1993). Trauma e melancolia. Percurso - Revista de Psicanálise, São Paulo, $10,50-55$.

Pinheiro, T. (2005). Depressão na contemporaneidade. Pulsional Revista de Psicanálise, 182, 101-109.

Pinheiro, T., Verztman, J., Vianna, D., Venturi, C., Caravelli, S. \& Canosa, L. (no prelo). Patologias narcísicas e doenças auto-imunes: a dimensão da temporalidade, Revista Psyquê.

Quintella, R. R. (2008). Vicissitudes da crença narcísica: a depressão no mundo contemporâneo. Tese de Doutorado. Programa de Pós-graduação em Teoria Psicanalítica. Universidade Federal do Rio de Janeiro, Rio de Janeiro, RJ.

Rorty, R. (1997). Escritos filosóficos I-objetivismo, relativismo e verdade. Rio de Janeiro: Relume Dumará.

Tchekhov, A. (2000). Ivanov. São Paulo: Edusp.

Verztman, J. S. (2002) O observador do mundo: a noção de clivagem em Ferenczi. Revista Agora, 5, 59-78. 


\section{Notas}

1 Cabe frisar que não estamos tomando a dimensão discursiva como única vertente da constituição subjetiva, mas um aspecto a partir do qual desenvolver-se-á, neste trabalho, a noção de crença narcísica e suas consequências no campo da depressão.

2 Este desenvolvimento teórico faz parte da Tese "Vicissitudes da crença narcísica: a depressão no mundo contemporâneo" (Quintella, 2008), defendida no Programa de Pós-Graduação em Teoria Psicanalítica da UFRJ, orientada pela Professora Teresa Pinheiro e coorientada pelo Professor Julio Verztman. Toma-se como principal referência as pesquisas desenvolvidas no Núcleo de Estudos em Psicanálise e Clínica da Contemporaneidade (NEPECC/UFRJ), coordenadas por Teresa Pinheiro e Julio Vertzman.

3 Na figuração clínica de Ferenczi, o trauma aparece como resultado do "desmentido" de uma cena de sedução na infância por parte de um adulto. De uma maneira resumida, o ato sexual do adulto é sentido pela criança como desprazeroso, porém ela o percebe dentro da linguagem da ternura, característica de seu universo lúdico, ao contrário do adulto, que teria realizado o ato de sedução dentro da linguagem da paixão. O adulto reage com uma culpa impossível de ser integrada à rede de representações da criança, o que gera uma impossibilidade do processo de introjeção. Esta circunstância subjetiva recai sobre a criança especificamente quando esta a relata a um terceiro, que desmente categoricamente o fato. O fator traumático é a impossibilidade de integrar o sentido da culpa ao jogo de linguagem da ternura. Diante de tal conjuntura, Ferenczi sublinha que o trauma se encontra na raiz da clivagem do eu, representando uma divisão radical que o coloca numa condição absolutamente frágil perante o outro. Ferenczi denomina "identificação com o agressor" o resultado de tal impossibilidade introjetiva. Nessa circunstância, o adulto desaparece inteiramente da realidade externa e assume todo o espaço de reconhecimento de si da criança. Este tipo de identificação é similar à identificação narcísica de Freud e impede que a criança construa um universo subjetivo pautado na percepção de que os investimentos que dirige ao mundo são seus. Sublinha-se precisamente que a chamada "identificação com o agressor" é uma tentativa paradoxal e desesperada de introjeção, na medida em que o que está jogo nessa circunstância é a significação do ocorrido.

$4 \mathrm{O}$ autor aborda a introjeção como um dos processos fundamentais do aparelho psíquico. Segundo o autor, o aparelho psíquico trabalha constantemente para "apropriar-se" de objetos para sua "introdução" no eu. Para Ferenczi, o psiquismo se movimenta no sentido da introjeção e, se ele investe de libido um objeto é para, em última instância, introjetá-lo (Ferenczi, [1912] 1991).

5 Apresentação de Patrícia Saceanu da obra Ivanov no II Encontro de Itatiaia - "Patologias narcísicas e mundo contemporâneo - depressão e melancolia", coordenado por Teresa Pi- 
nheiro e Julio Vertzman, que contou com a presença da Prof. Marie-Claude Lambotte da Universidade de Paris VII, em 2004. O tema de Ivanov foi também trabalhado por Teresa Pinheiro em seu artigo "Depressão na contemporaneidade", ao qual fazemos referência, publicado em Pulsional - Revista de psicanálise, ano XVIII, 182, junho de 2005, 101-109.

6 O chamado ego infantil do narcisismo primário (eu ideal) é, por definição, irrecuperável, posto que fundado numa crença e num discurso que não se sustenta no tempo (Sua Majestade o Bebê). O problema não reside, portanto, na impossibilidade de recuperação, mas na forma como o sujeito irá se defrontar com a transitoriedade de sua crença, ou seja, como ele irá subjetivar e dar encaminhemento à impossibilidade de sua perfeição narcísica bem como à mutabilidade de sua condição.

7 Essa questão do "tudo ou nada" na depressão é portanto a medida objetiva de uma autoimagem irreconciliada. Ivanov, por exemplo, nega-se a tal conciliação entre passado e presente - marca da transitoriedade -, mergulhando numa depressão aguda. Na melancolia o "tudo ou nada" apresenta-se de outra forma. Ali, o sujeito recrimina-se a si mesmo pela impossibilidade do "tudo" que o objeto deveria comportar - como que num aviltamento à imperfeição do objeto -, a mãe toda-potente. Identificado narcisicamente a este objeto, o melancólico denuncia, revela e desvela a imperfeição, tornando-se seu senhor e fazendo dela sua única condição existencial. A diferença fundamental entre a melancolia e a depressão é que, se o deprimido referencia-se num passado perdido, o melancólico afirma nunca ter vivido qualquer experiência parecida, localizando a verdade trágica de seu desvalor num sempre infindável, tanto para frente como para trás no tempo.

8 Para um aprofundamento sobre a questão da temporalidade, ver Pinheiro, T. et al. (no prelo). Patologias narcísicas e doenças auto-imunes: a dimensão da temporalidade, Revista Psyquê.

Recebido em 02 de setembro de 2009 Aceito para publicação em 09 de março de 2010 